\title{
An IPD Approach to Construction Education
}

\author{
Jennifer MacDonald, (University of Technology Sydney, Australia)
}

Julie Mills, (University of South Australia, Australia)

\begin{abstract}
The construction industry worldwide is moving towards more collaborative working practices, such as integrated project delivery (IPD). The era of the Master Builder has passed; modern construction projects are too complex for one person to understand all aspects. New specialist disciplines are emerging, with experts engaged at earlier stages of the design process. However, this collaborative approach is not reflected in the current education of architecture, engineering, and construction (AEC) professionals. Students of the separate disciplines are generally educated in isolation from the others. On graduation, they are then expected to be able to work in integrated teams without prior training in multidisciplinary teamwork. This contributes to the poor levels of trust and inadequate information sharing that plague the industry and prevents it from fully embracing the productivity savings that BIM (building information modelling) and IPD promise. Academics of the AEC disciplines also work in isolation, and the same courses are developed from scratch every time a new academic arrives at an institution. This paper proposes an integrated approach to the teaching of AEC subjects, including a framework to assist academics in adapting their existing curricula, and reports on some initial trials carried out in three Australian Universities.
\end{abstract}

Keywords: Building Information Modelling (BIM), PLIM, IPD, Collaborative education framework

\section{Introduction}

Academics in the architecture, engineering and construction (AEC) disciplines are currently facing enormous changes due to disruptive technologies and processes emerging in both the higher education sector and the wider construction industry. Governments are demanding that universities prove their worth as education providers and research generators in order to secure further public funding. At the same time, universities in general are also facing pressure from the "Google Generation": the rise of Massive Open Online Courses (MOOCs) and other free or low-cost courses provided over the internet means that students have more choice in their courses and may be less willing to pay high fees for traditional chalk-and-talk transmission-style classes in Universities. The construction industry is also facing disruptive changes, due to the on-going global financial crisis and the introduction of new technologies and processes, such as building information modelling (BIM). However, in general, AEC curricula have not been adapted to reflect these industry changes.

Construction is a litigious, inefficient industry, with low levels of trust and poor information sharing. Various sources estimate that inadequate documentation contributes an average of $10-15 \%$ to typical project delivery costs (e.g. Woolstenholme (2009); Allen Consulting Group (2010)). Innovative construction projects employing collaborative, Integrated Project Delivery (IPD) methods and BIM technologies have been shown to deliver better, energy efficient products for their clients, while saving costs on delivery through reduced requests-forinformation (RFIs) and re-work (e.g. Bernstein, 2012 ). However, the current shortage of building design professionals, trained in collaborative design and construction practices, remains a barrier to universal adoption of collaborative working practices in the industry. 
Just as industry must undergo a paradigm shift from its old combative culture to one of integration and information sharing, so must academia.

The need for a framework to support adoption of collaborative design education by Architecture, Engineering and Construction (AEC) schools has been stated previously (Macdonald \& Mills, 2011). A framework (called the "IMAC Framework"), to support academics in adapting their curricula to include collaborative learning and working techniques, with the assistance of BIM tools and processes, has been developed with the aid of an OLT (Australian Office of Learning and Teaching) grant. This paper discusses current trends in multidisciplinary AEC education and the progress of the IMAC trial in three Australian partner institutions.

\section{Innovate to Survive: Reality for Both Industry and Academia}

The global financial crisis has driven many businesses to the wall and many of the survivors have realised they need to innovate to win further work, and to be more efficient in the way they work in order to survive. Interestingly, this trend seems most apparent in countries whose economies, and construction industries, have been hardest hit (in the US and UK in particular) and less so in better-off economies such as Australia's (Allen Consulting Group, 2010). This effect is illustrated by Teicholz' graph (Teicholz, 2013) (Fig. 1), which shows a moderate increase in real value added per US construction employee in the years after the 2007 downturn. However, the graph also illustrates the poor performance of construction compared to the manufacturing industry over the same period (the upper line indicates manufacturing). Even without factoring in the effects of the downturn, construction productivity has declined over the past 30 years (Teicholz, 2004).

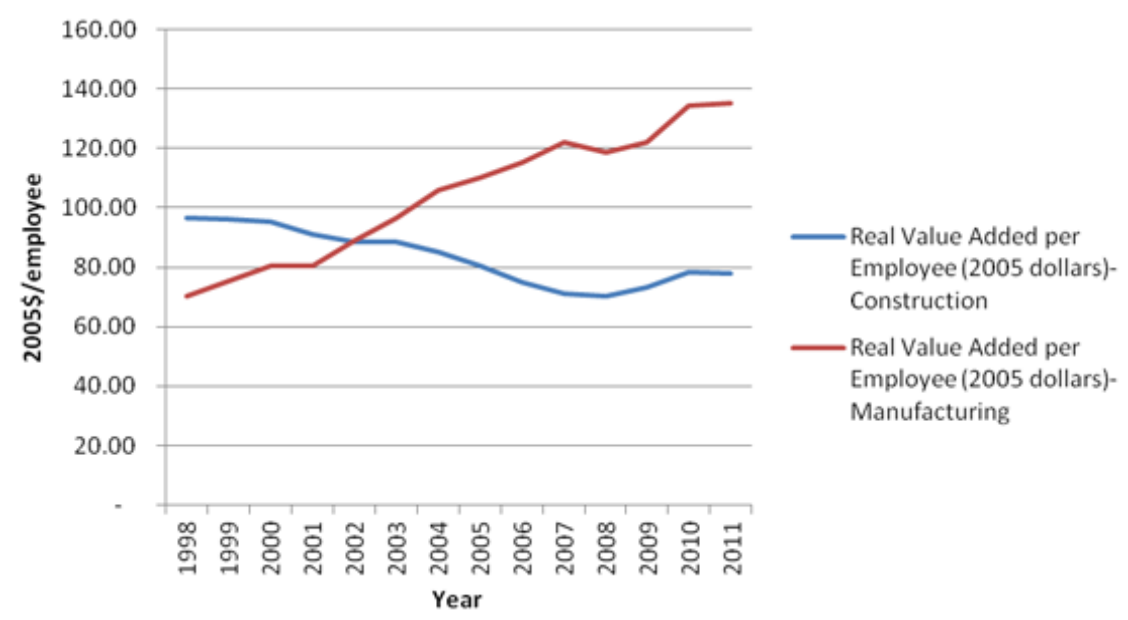

Figure 1 Value Added per US Employee in 2005 dollars Source: Teicholz (2013)

The construction industry is extremely fragmented and lacking integration (NIST, 2004; Woolstenholme, 2009). Additionally, reports show that the quality of project documentation has declined over the past 20 years and that poor documentation is contributing an additional 10 to $15 \%$ to project costs. $60-90 \%$ of all variations are due to poor design and documentation (QCIF, 2005). It is worth noting, here, that the introduction of computer aided drafting (CAD) tools, far from improving the quality of documentation, has actually coincided with its decline.

In an attempt to achieve greater efficiencies, and echoing earlier changes adopted by the car and manufacturing industries, the construction industry worldwide is moving towards more collaborative working practices, aided by building information modelling (BIM) tools and processes. Collaboration between multidisciplinary, trans-global AEC teams is becoming commonplace (O'Brien et al., 2003). Globalisation means that consultants can work from

MacDonald, J and Mills, J (2013) 'An IPD approach to construction education', Australasian Journal of Construction Economics and Building, 13 (2) 93-103 
almost anywhere in the world and building elements can be prefabricated offshore and simply assembled on site. In the future, construction workers are likely to become assembly workers as prefabrication takes over. The increasing complexity of our buildings also means that our construction professionals must collaborate at earlier stages on jobs to produce the best result for clients. However, for the industry to move wholesale into integrated, collaborative practices, a seismic change is required in its culture. The culture of the construction industry has traditionally been very pugilistic, with minimal trust between parties on projects, aided by an atmosphere of litigation and punitive contracts. This lack of trust does not encourage information sharing and collaboration. Industry needs to move from the current culture of fragmentation, litigation, mistrust, and withholding of information to one of open-ness, collaboration, teamwork, and trust if it really wants to maximise the potential of BIM and improve overall productivity.

The current models for teaching students of the AEC disciplines do not support the new demands from both academia and industry. However, there is also a great opportunity to rethink the way AEC courses are developed and to become more efficient in delivering them. Holland et al. (2010) describe the need for "T-shaped people" in the construction teams of the future; that is to say, people who have deep knowledge of their own professional discipline, but who also have broad knowledge of the other disciplines in the team.

\section{Awash in Acronyms: Defining BIM or PLIM or..?}

The uptake of BIM has snowballed in recent years but at the same time "BIM" has become a fashionable marketing term, promoted by software vendors. Unfortunately, these vendors have led some professionals to think that to "do BIM" they simply have to purchase a 3Drendering software package. Some industry figures have coined the term "BIMwash" to describe the phenomenon whereby many firms are claiming to be "doing BIM" but very few are using it to its full potential and integrating with all the other construction disciplines (Miller, 2009).

Despite the glossy marketing materials produced by various software manufacturers, there is still no universally accepted definition for BIM. BIM is not a software product, but an approach to creating and managing information about projects. The term "Building Information Modelling" appeared in print (in English) in 1992 (van Nederveen \& Tolman) though, as stated previously, the tools and processes and ideas have been evolving since at least the 1970s (e.g. Eastman, 1975) and many of the processes mimic those adopted by the car industry decades ago, such as just-in-time manufacturing (JIT). BIM can be a noun (the building information model) or a verb (the modelling process). Additionally, the individual words making up the acronym can mean different things to different professionals:

(B) Building can apply to a single building envelope or the wider built environment;

(I) Information is really the most important part of the acronym, as the concept is all about creating and sharing quality information about a project and not losing or recreating information when moving between phases;

(M) $\mathbf{M}$ originally stood for Modelling or Model but current literature tends towards the more appropriate definition of Management (e.g. Race, 2012).

The major problem with the term "building information modelling" is that it is inadequate for describing the complexity involved in creating and managing information over the lifecycle of construction projects, whatever their scale. Race (2012) proposes borrowing from the acronym PLM (product lifecycle management) and replacing BIM with PLIM (Project Lifecycle Information Management), as this is a more accurate indication of the intent to create a comprehensive package of information representing the life of a facility.

MacDonald, J and Mills, J (2013) 'An IPD approach to construction education', Australasian Journal of Construction Economics and Building, 13 (2) 93-103 


\title{
Overcoming Institutional Inertia
}

\begin{abstract}
Many academic programs still produce students who expect they will spend their careers working as heroic, solitary designers. But integrated practice is sure to stimulate a rethinking of that notion. Pedagogy must focus on teaching not only how to design and detail, but also how to engage with and lead others, and how to collaborate with the professionals they are likely to work with later. Pressman (2007), (p3)
\end{abstract}

Since engineering and architecture emerged as separate professional disciplines, AEC students have been educated in isolation from each other. Starzyk and McDonald (2010) note that the focus of architectural education in the past was on developing individual skills such as being able to draw. Now, they state, "the importance of personal skill is yielding to the primacy of collective knowledge".

The complexity of modern building projects and technologies means that nobody can be a master of all anymore. Often the professions do not have a deep understanding of the information that each requires at different stages of a project. Time is thus wasted stripping out and even rebuilding models, when the models could have been set up more efficiently from the start of the process and unnecessary detail excluded prior to model exchange. If students are educated to work collaboratively and to learn the requirements of the other disciplines before they graduate, this level of misunderstanding is likely to be removed in future and trust improved. However, In order to bridge the disciplinary silos in industry, we need to start by breaking down the silos that exist in academia.

\section{A Thorny Question: Are We Educating or Training?}

The concept of creating job-ready graduates brings to the fore the "training vs. educating" debate. Traditionally, Universities have focused on teaching theory, with many faculty members believing that it is industry's role to train incoming graduates in job-related skills. The authors have frequently heard the refrain "we're not teaching students to press buttons" being used among educators who believe that BIM is just another CAD tool. However, the uptake of BIM is facilitating process, technological, and cultural changes, and its benefits extend far beyond mere visualization: students cannot be expected to "teach themselves BIM" any more than they could be expected to "teach themselves structural engineering". BIM actually provides a great opportunity to engage students more effectively and to aid understanding of how buildings are constructed. Hardy, quoted in Deutsch (2011, p 202) states:

When I look at the logic of construction means and methods that BIM inherently teaches, I see the potential to educate...

Any major change process is likely to encounter resistance. Some of the difficulties for academia in introducing BIM may include:

1. Questions about how to fit new topics into a crowded curriculum.

2. Reluctance to change teaching habits established over many years.

3. For those who may have developed their own niche or expertise, there may be resistance to take on a new subject, about which they are not an expert, or to retrain in an area they are not familiar with.

4. As the technologies supporting BIM evolve at a rapid pace, academics who have been out of industry for some time may feel overwhelmed trying to keep abreast of them.

5. The traditional silos of architecture, engineering and construction schools can be difficult to bridge. As in industry, mistrust of the other professions also exists in academia, and questions can arise as to who is responsible for (and who will pay for) cross-disciplinary courses. "The biggest hurdle is with true interdisciplinary efforts due

MacDonald, J and Mills, J (2013) 'An IPD approach to construction education', Australasian Journal of Construction Economics and Building, 13 (2) 93-103 
to conflicting student/faculty schedules and lack of compensation for more than one faculty member involved in a course" (Architectural Engineering Lecturer quoted in Vogt $(2010$, p 26)

6. Size of classes. Particularly in Australia, many academics face class minimum class sizes of 80 students, and the resources and time required to convert large cohort standard lecture-based courses into smaller multidisciplinary teamwork-based courses may seem an insurmountable challenge.

Motivation may also play a factor in the success of developing integrated curricula. The main motivation for industry to move towards collaborative working and the use of BIM has been pressure from major Clients and various governments, and the opportunity for improved profits and competitiveness. AEC educators are not generally subject to these same pressures. However, the construction industry has expressed a need for graduates skilled in collaborative building design and BIM. For example, the Built Environment Industry Innovation Council (BEIIC) wrote to all the Deans of Australian Built Environment Faculties in June 2010 to enquire as "to what extent the universities are embracing new technologies such as BIM and equipping our future professionals with cutting edge experience" (BEIIC, 2010). The Australian National BIM Initiative defines multi-disciplinary AEC education as one of six key areas needing support from both industry and government (buildingSMART, 2012).

The AEC professional bodies are also beginning to apply pressure to academic institutions to develop integrated courses, through proposed changes to accreditation criteria. For example, the Australian Institute of Architects (AIA) and Consult Australia set up a joint BIM and IPD task force in 2012 (AIA, 2012), including a dedicated BIM in Education Working Group.

\section{CODE BIM: Collaborative Design Education using BIM}

The Australian Office of Learning and Teaching (OLT) has funded a project to develop a framework to assist AEC academics in introducing collaborative courses utilising BIM tools and processes. The Australian partner institutions in this project are the University of Technology, Sydney, the University of South Australia and the University of Newcastle.

The initial stages of the project involved benchmarking current practice in academic institutions worldwide. According to Barison and Santos (2010), the majority of US institutions (excepting pioneers such as Georgia Tech) began to introduce BIM in their courses from 2002, and it is a rapidly developing field. For example, Morse (2009) lists eight US Academic Institutions and records survey responses from them indicating that $82 \%$ were providing formal teaching in BIM. A current web search reveals that $100 \%$ of the institutions listed by Morse now teach BIM in some of their courses, at least 17 of the $18(94 \%)$ ABETaccredited Architectural Engineering programs in the US now offer some level of BIM instruction, and at least 9 out of the 12 ABET accredited Construction Engineering institutions offer BIM courses (75\%) (Macdonald, 2011a).

To explore further the current practice and understanding of BIM and collaborative AEC education amongst AEC faculty, interviews were conducted with senior AEC academics and researchers from four leading Universities in Australia, three in the UK, one in Sweden, two in the Netherlands, one in Canada and five in the USA, over a period of two years. Some results of this study were reported previously (Macdonald \& Mills 2011). In 2010, the author was also involved in conducting a large on-line industry survey of AEC professionals and educators across Australia and New Zealand. The responses from the academic sector to this survey indicated that around $70 \%$ were using BIM at some level within their schools.

The most successful implementations of collaborative courses have been between Schools housed within the same financial unit (whether that is a faculty or department). For example,

MacDonald, J and Mills, J (2013) 'An IPD approach to construction education', Australasian Journal of Construction Economics and Building, 13 (2) 93-103 
Penn State has implemented extremely successful capstone courses involving collaborative groups of students from its four architectural engineering disciplines, architecture and landscape architecture, as described by Solnosky et al. (2013). It appears that academics around the world face the same issues in relation to overcoming bureaucratic hurdles, such as which school pays for teaching of another school's students. Some schools have found that it is easier to develop collaborative courses between institutions than across faculties within their own institution. For example, the University of Southern California (USC) has run graduate-level courses with students from Virginia Tech and the University of Texas at Austin. Stanford University has collaborated with Twente University, Netherlands, to develop graduate-level courses in construction management with BIM support (Peterson, et al., 2011) Other institutions have found that collaboration is easier when creating Masters-level courses, such as the Master of Design-Build program run jointly between Auburn University's Schools of Architecture and Building Science, and Salford University's Master of BIM and Integrated Design. So far, no university appears to have implemented fully collaborative courses across the three separate AEC disciplines at undergraduate level.

A striking difference observed between the US schools visited and those in Australia was typical class size. Class sizes continue to grow in Australia, boosted by the removal of government caps on entry numbers. However, staff numbers have not increased proportionally and it appears that many institutions have embraced larger and larger lectureformat classes to cope. BIM requires multidisciplinary collaboration, but it is very difficult to foster collaborative, technology-intensive teamwork in a classroom format consisting of a 3hour weekly lecture to over 90 students. The largest multi-disciplinary class observed in the US contained 25 students, and some had as few as six.

Lectures, both physical and online, involve a transmission style of teaching that tends to focus on the lower levels of the taxonomy of learning proposed by Bloom et al (1956). Where small group, collaborative, problem-based learning approaches excel is in promoting the higher levels of learning in the taxonomies. Saljo (1979) also defines deeper skills that students should develop, including making meaning and reinterpreting. The development of these types of skills is what Universities and other training providers should be focusing their efforts on. Transmission teaching just involves the broadcasting of data to a largely passive audience: knowledge cannot be transmitted into someone else's head.

\section{IMAC: Illustration, Manipulation, Application, Collaboration}

The development of a framework to support academics to incorporate collaborative design principles in their curricula has been described in detail previously (Macdonald, 2012). The framework comprises four key stages: Illustration, Manipulation, Application and Collaboration (IMAC). These stages do not necessarily always follow the years of a degree course, but can be viewed as building blocks of learning. The framework comprises two components: a benchmarking tool and a separate guide to implementation.

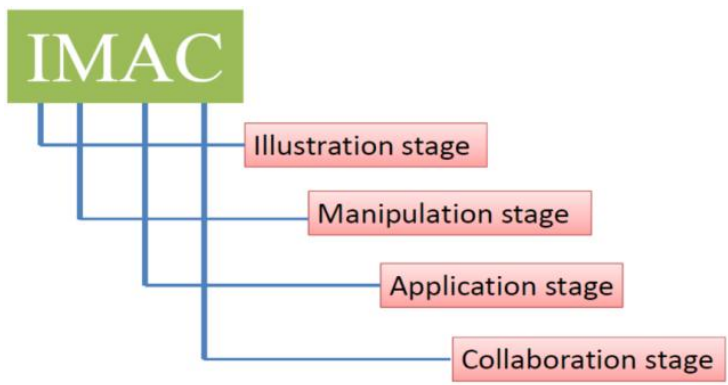

Figure 2 The four stages making up the IMAC framework

MacDonald, J and Mills, J (2013) 'An IPD approach to construction education', Australasian Journal of Construction Economics and Building, 13 (2) 93-103 
The stages have been mapped to various levels on the taxonomy of learning proposed by Bloom et al (1956) and expanded by Krathwohl et al (1964). As the IMAC framework aims to assist development of both technical (I.T and discipline-specific) and interpersonal (collaborative and teamwork) skills, it straddles the cognitive and affective domains.

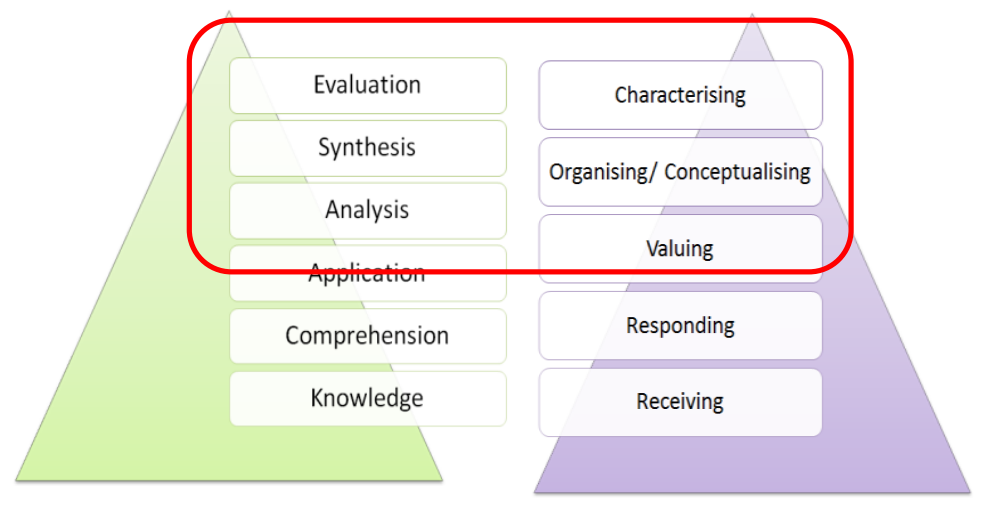

Figure 3 Bloom's Taxonomy of Learning: Cognitive (L) and Affective (R) Domains (Bloom et al., 1956; Krathwohl et al, 1964)

The framework does not dictate in which academic year each stage should be introduced. Students from the different AEC disciplines study courses of varying lengths and some skills are introduced earlier in some courses than others. For example, students of architecture tend to be introduced to modelling tools from first year whereas students of structural engineering might only be introduced to them in third year. It may also be possible to progress between stages within one academic year. The framework also considers suitable delivery methods at each stage, aiming to achieve deeper levels of learning as students progress through their education.

The benchmarking component of the IMAC framework has been used to benchmark existing courses at the three institutions and to plot targets for future curriculum developments. The framework recognises that the different disciplines will not be aiming to achieve full collaboration in all courses or areas - for example, architecture graduates will be expected to be able to create full BIM models from scratch whereas engineers and construction managers would usually only be expected to be able to manipulate existing models for their own analysis purposes. The framework tool thus suggests different targets (shaded, refer Fig 4) for the different discipline areas, and it is expected that these will be mapped to professional accreditation criteria as these are developed.

\begin{tabular}{|c|c|c|c|c|c|c|c|c|c|c|c|}
\hline & $\begin{array}{c}\text { BUILDING } \\
\text { TECHNOLOGY }\end{array}$ & \multicolumn{2}{|c|}{ ENVIRONMENT } & \multicolumn{3}{|c|}{ MANAGEMENT } & \multicolumn{2}{|c|}{ IT } & \multicolumn{3}{|c|}{ SPECIALISM } \\
\hline & Framing & Materials & Sustainability & People & Communication & Teamwork & $\begin{array}{l}\text { General } \\
\text { IT }\end{array}$ & $\begin{array}{l}\text { BIM } \\
\text { tools }\end{array}$ & A & E & c \\
\hline \multicolumn{12}{|l|}{ Collaboration } \\
\hline \multicolumn{12}{|l|}{ Application } \\
\hline \multicolumn{12}{|l|}{ Manipulation } \\
\hline \multicolumn{12}{|l|}{ Illustration } \\
\hline 0 Not Used & & & & & & & & & & & \\
\hline
\end{tabular}

Figure 4 IMAC chart for an Engineering Course (suggested Target Levels shaded)

MacDonald, J and Mills, J (2013) 'An IPD approach to construction education', Australasian Journal of Construction Economics and Building, 13 (2) 93-103 
The project considers two separate aspects of collaboration: collaborative working and collaborative learning. Collaborative working involves student teams tackling project-based tasks that simulate the new collaborative industry working practices. In other words, they are collaborating to achieve a goal (e.g. the design of a building). By contrast, for collaborative learning it is the learning itself that is the goal. There is a large body of pedagogical research showing that students engage and learn much better through teamwork and team learning. The Stoic philosopher Seneca stated that, "by teaching we learn", and the theory that students learn more from teaching has been proven through research (Annis, 1983; McKeachie et al, 1986). The teacher acts more like a peer in the collaborative environment.

\section{Assessing the IMAC Curriculum Framework}

The IMAC framework is being trialled at three Australian partner institutions, across a variety of year levels and disciplines. Data will be collected from these trials during the Spring and Autumn 2013-2014 semesters. The curriculum assessment methodology that will be followed is similar to that described by Mills (2002), based on earlier research by Rosier and Keeves (1991) and Treagust (1987). This methodology is based on dividing the curriculum into four stages, namely: (1) intended; (2) implemented, (3) achieved and (4) perceived. Mills (2002) summarises the details of the stages as shown in Table 1, below. Jackson (1992) also describes a similar four-step approach to evaluating the curriculum, for which he suggests the terms (1) official; (2) enacted; (3) delivered and (4) experienced. Jackson's terms are shown in brackets in Table 1.

\begin{tabular}{|c|c|}
\hline Stage & Description \\
\hline Intended (Official) Curriculum & $\begin{array}{l}\text { The original vision underlying a curriculum, possibly in } \\
\text { the form of a national curriculum document or } \\
\text { accreditation criteria. Within a particular course, this } \\
\text { may be presented in the form of a course or subject } \\
\text { document }\end{array}$ \\
\hline Implemented (Enacted) Curriculum & The actual instructional process as implemented \\
\hline Perceived (Delivered) Curriculum & $\begin{array}{l}\text { The actual learning experiences as perceived or } \\
\text { experienced by the students }\end{array}$ \\
\hline Achieved (Experienced) Curriculum & The resulting learning outcomes of the students \\
\hline
\end{tabular}

Table 1 The Four Stages of Curriculum for Evaluation (Mills, 2002)

In terms of assessing the effectiveness of the IMAC curriculum framework, it will not be possible (due to the two-semester time constraint) to assess students going through the entire four-stages of the framework. Instead, selected existing courses at different stages have been selected to trial best-practice collaborative modifications. These will be used as case studies for the research. Course co-ordinators will be asked to supply their course objectives (learning objectives) in order to determine the intended curriculum. The other stages of the curriculum will be assessed using pre- and post- course surveys, classroom observation, journals, reviews of artefacts produced and focus groups.

\section{Conclusions and Some Proposals}

In response to some of the questions raised earlier in this paper, integrating principles of collaboration and BIM technologies into existing classes throughout the curriculum should reduce the need to develop completely new courses. Bolt-on capstone courses, though useful as a first foray into collaborative courses, do not constitute curriculum renewal. In order to encourage true curriculum renewal, the professional bodies should update their accreditation criteria to reflect the industry need for graduates skilled in BIM and collaborative working. Accreditation criteria provide the greatest incentive for academic institutions to instigate changes to their curricula.

MacDonald, J and Mills, J (2013) 'An IPD approach to construction education', Australasian Journal of Construction Economics and Building, 13 (2) 93-103 
Ironically, the industry problem that is creating huge demand for BIM-related courses is also one that affects employers of academics: how to recruit (or train) and then retain teaching staff skilled in the areas of collaborative working and BIM technologies? This is a particularly difficult question given the high demand, and consequently high salaries, on offer in industry. Many universities are reliant on assistance from guest tutors from industry when introducing technical courses in BIM, but it would be wise for these institutions to develop strategies to capture this external knowledge and train faculty members in addition to their students. AEC education should perhaps take its cue from Integrated Practice in the construction industry by looking at ways to become more efficient and collaborative. Why, for example, should institutions not pool their resources for the teaching of lower level courses and use their valuable faculty to deliver more intensive courses at higher levels? For example, engineering mathematics and statistics classes tend to cover the same content all over the world. An excellent lecturer could be nominated from one institution to provide a definitive online course on one topic that students in all engineering courses are required to pass in their own time before progressing to more advanced in-class courses. This is not really too dissimilar to many institutions setting textbooks that have been written by academics in other universities.

The author has attended many BIM workshops and conferences over the past few years and it seems that general questions from industry have moved on from "what is BIM and why should we adopt it?" to "we accept that we need to adopt BIM, now how do we go about doing so?" Although AEC academics (with notable exceptions) generally appear to be at the earlier stage of questioning, it is likely that they will also move towards the question of implementation, and the framework described should provide assistance in this. The future belongs to the integrators!

I am looking for a lot of men who have an infinite capacity to not know what can't be done... [Henry Ford]

The IMAC framework will be trialled in the Australian partner institutions over the Spring and Autumn Semesters 2013-2014 and the results published in late 2014. More information can be viewed at http://codebim.com

\section{References}

AIA (2012) BIM and IPD Steering Committee, Documents produced by the four working groups are available online: http://www.bim.architecture.com.au/groups/

Allen Consulting Group (2010) Productivity in the buildings network: assessing the impacts of Building Information Models, report to the Built Environment Innovation and Industry Council, Sydney, October 2010

Annis, L. F. (1983) 'The process and effects of peer tutoring', Human Learning, 2, 39-47

Barison, M.B., Santos, E.T. (2010) 'BIM teaching strategies: an overview of the current approaches' in Proc. of the International Conference on Computing in Civil and Building Engineering, Nottingham, 2010

BEIIC (2010) Letter to all Deans of Australian Built Environment Faculties, Unpublished

Bernstein, H.M. (e.d.) (2012) SmartMarket Report: The Business Value of BIM in North America, McGraw-Hill Construction, Bedford, MA., USA

Bloom, B.S., Englehart, M.D., Furst, E.J., Hill, W.H., Krathwohl, D.R. (1956) The Taxonomy of Educational Objectives, The Classification of Educational Goals, Handbook I: Cognitive Domain, David McKay Company, New York, NY

buildingSMART (2012) The National BIM Initiative, Report to DIISRTe, June 2012, Available http://buildingsmart.org.au/nbi-folder/NationalBIMlniativeReport 6June2012.pdf

MacDonald, J and Mills, J (2013) 'An IPD approach to construction education', Australasian Journal of Construction Economics and Building, 13 (2) 93-103 
Deutsch, R. (2011) BIM and Integrated Design: Strategies for Architectural Practice, John Wiley \& Sons, Inc., New Jersey

Eastman, C. (1975) 'The use of computers instead of drawings in building design', AIA Journal, March, 63 (3), 46-5

Holland, R., Messner, J., Parfitt, K., Poerschke, U., Pihlak, M., Solnosky, R., (2010) 'Integrated Design Courses Using BIM as the Technology Platform', National Institute of Building Sciences, Annual Meeting of EcoBuild America Conference, December 7, 2010, Washington, DC

Jackson, P. (1992) Conceptions of curriculum and curriculum specialists, In P. Jackson (Ed.), Handbook of Curriculum Research, 3-40, New York: MacMillan

Krathwohl, D.R., Bloom, B.S., Masia, B.B. (1964) The Taxonomy of Educational Objectives: The Classification of Educational Goals, Handbook II: Affective Domain, David McKay Company, New York, NY

Macdonald, J.A. \& Mills, J.E. (2011) 'The Potential of BIM to Facilitate Collaborative AEC Education', American Society for Engineering Education Annual Conference, Vancouver, Canada, June 2011, in Proceedings of the 118th ASEE Annual Conference, American Society of Engineering Education, Vancouver, Canada

Macdonald, J.A. (2011a) 'BIM - Adding Value by Assisting Collaboration', LSAA 2011 Conference, Novotel, Sydney Olympic Park, October 2011 in Proceedings of LSAA 2011 Conference, ed. Kneen, P., Lightweight Structures Association Australia, Sydney. Paper available at http://codebim.com/bim-library/codebim-project-publications/

Macdonald, J.A. (2012) 'A framework for collaborative BIM education across the AEC disciplines. $37^{\text {th }}$ Annual Conference of Australasian University Building Educators Association (AUBEA), 4-6 July 2012, Sydney Australia

McKeachie, W. J., Pintrich, P. R. Lin, Y.-G, \& Smith, D. A. F. (1986) Teaching and Learning in the College Classroom: $A$ Review of the Research Literature. Ann Arbor: University of Michigan, National Center for Research to Improve Postsecondary Teaching and Learning

Miller, R. (2009) 'The BIM Mirage or BIMwashing', online blog entry in The Commercial Real Estate Revolution, October 2009, available http://thecrerevolution.com/2009/10/the-bimmirage-or-bimwashing/

Mills, J.E. (2002) The Effectiveness of Project-Based Learning in Structural Engineering, $\mathrm{PhD}$ Thesis, Curtin University, available at http://espace.library.curtin.edu.au/R?func=dbinjump-full\&local base $=$ gen01-era02\&object id $=12603$

Morse, E. J. (2009) An Online Case Study Resource For Building Information Modeling In College Education. (Worcester Polytechnic Institute). Available at http://www.wpi.edu/Pubs/E-project/Available/E-project-090109-010641/unrestricted/EJMBIMinEducation.pdf

NIST (National Institute of Standards and Technology) (2004) Cost Analysis of Inadequate Interoperability in the U.S. Capital Facilities Industry. NIST GCR 04-867. Gaithersburg, Md.: NIST

Pressman, A. (2007) 'Integrated Practice in Perspective: A New Model for the Architectural

Profession', Architectural Record, May 2007,

http://archrecord.construction.com/practice/projDelivery/0705proj-3.asp

QCIF (Queensland Construction Industry Forum) (2005) Getting it Right First Time

O’Brien, W., Soibelman, L., Elvin, G. (2003) 'Collaborative Design Proceses: An Active- and Reflective- Learning Course in Multidisciplinary Collaboration', Journal of Construction Education, Summer 2003, 8 (2), 78-93

MacDonald, J and Mills, J (2013) 'An IPD approach to construction education', Australasian Journal of Construction Economics and Building, 13 (2) 93-103 
Peterson F., Hartmann T., et al. (2011) 'Teaching construction project management with BIM support: Experience and lessons learned.' Automation in Construction, 20, 115-125

Race, S. (2012) BIM Demystified: An Architect's guide to Building Information Modelling/Management (BIM), RIBA Publishing, London

Rosier, M.J. \& Keeves, J.P. (Eds.) (1991) The IEA study of science I: Science education and curricula in twenty-three countries, Pergamon Press, London

Säljö, R. (1979) 'Learning in the learner's perspective: 1. Some common-sense conceptions', Reports from the Institute of Education, University of Gothenburg, 76

Solnosky, R., Parfitt, M., and Holland, R. (2013) 'An IPD and BIM Focused Capstone Course Based on AEC Industry Needs and Involvement.' J. Prof. Issues Eng. Educ. Pract., 10.1061/(ASCE)El.1943-5541.0000157 (Feb. 28, 2013)

Starzyk, G.F. and McDonald, M. (2010) 'The Collaborative Dance: Only Three Steps' in Proc of the BIM-Related Academic Workshop, December 7-9 2010, Washington DC, eds. Salazar, G. and Issa, R.

Teicholz, P. (2004) 'Labor productivity declines in the construction industry: causes and remedies'. AECbytes Viewpoint, Issue 4, April 14

Teicholz, P. (2013) 'Labor-Productivity Declines in the Construction Industry: Causes and Remedies (Another Look)'. AECbytes Viewpoint, Issue 67, March 14

Treagust, D.F. (1987) 'Exemplary Practice in High School Biology Classes' in Tobin, K.G. \& Fraser, B.J. (eds.) Exemplary practice in science and mathematics education, 29-44, Curtin University of Technology, Perth

van Nederveen, G.A. \& Tolman, F. (1992) 'Modelling Multiple Views on Buildings', Automation in Construction, December, Vol 1, Number 3, pp215-224

Vogt, B.A. (2010) Relating Building Information Modeling \& Architectural Engineering Curricula, Department of Architectural Engineering, Kansas State University, MSc Thesis

Wolstenholme (2009) Never Waste a Good Crisis: A Review of Progress since Rethinking Construction and Thoughts for Our Future, Constructing Excellence, October 2009, available online: www.constructingexcellence.org.uk/pdf/Wolstenhome Report Oct 2009 